\title{
Staphylococcus coagulase-negativos resistentes a drogas isolados de leite de búfalas (Bubalus Bubalis)
}

\section{Drug resistant coagulase-negative Staphylococci isolated from milk of buffaloes (Bubalus Bubalis)}

\author{
Isabel Cristina Fábregas Bonna, ${ }^{*}$ Ana Paula Vargas dos Santos, ${ }^{* *}$ Gina Nunes Teixeira, ${ }^{* * *}$ Olney Vieira-da-Motta ${ }^{* * *}$
}

\begin{abstract}
Resumo
A mastite causa prejuízos econômicos para criadores de gado leiteiro, compromete a produção e altera a composição do leite. O leite mastítico e seus derivados podem representar risco à saúde pública, pela veiculação de microrganismos resistentes a antibióticos. Entre os microrganismos envolvidos nas infecções intramamárias estão os Staphylococcus coagulase-negativos (SCN). Este trabalho teve como objetivo isolar cepas de SCN do leite de búfalas e testar sua resistência frente a drogas antibacterianas. Foram coletadas 400 amostras de leite de seis municípios do estado do Rio de Janeiro. Os cocos Grampositivos foram testados para a produção de catalase, oxidase, coagulase, desoxiribonuclease e fermentação de manitol e as colônias avaliadas pelo aspecto morfológico, hidrólise de esculina e atividade hemolítica. Ao todo 197 isolados de SCN foram estudados. O perfil de sensibilidade ou resistência das bactérias às drogas foi avaliado pelo método de difusão em agar. Observou-se maior padrão de resistência frente aos beta-lactâmicos, penicilina, amoxicilina, ampicilina (média $51,77 \%$ ) e o menor frente a cefalotina, vancomicina, cefoxitima e a gentamicina com $0 \%$ de resistência. A presença de um isolado de Staphylococcus sciuri com perfil intermediário a vancomicina foi discutida.
\end{abstract}

Palavras-chave: Staphylococcus coagulase-negativos, resistência, búfalos.

\begin{abstract}
Mastitis represents a serious economic loss for dairy farmers, interfering and altering the production and quality of milk. Mastitic milk and dairy products may represent a public health problem as vehicle of antibiotic resistant microorganisms. Coagulasenegative staphylococci (CNS) are among the main microorganisms involved in intramammary infections. The aim of this work was to isolate CNS present in milk of buffaloes and testing their resistance towards antibacterial drugs. Four hundred samples of milk were collected from six municipalities of Rio de Janeiro State. All Gram-positive cocci were tested for coagulase, catalase, oxidase and aerobic mannitol fermentation, and evaluation of colony morphology, esculin hydrolysis, hemolytic pattern, and deoxyribonuclease production. A total of 197 CNS isolates were studied. To determinate the sensitivity or resistance of bacteria to antibiotic the agar disk diffusion method was used. The highest level of resistance of staphylococci was towards beta-lactamics penicillin, amoxicillin and ampicillin $(51,77 \%$ average) and the lowest towards cephalothin, vancomycin, cephoxytime, and gentamicin revealing $0 \%$ resistance profile. The presence of one isolate of Staphylococcus sciuri with a intermediary profile towards vancomycin was discussed.
\end{abstract}

Keywords: Coagulase-negative Staphylococci; resistance; buffalos.

\section{Introduçâo}

A presença de microrganismos resistentes aos antibióticos no meio rural, principalmente na área veterinária, está diretamente relacionada com o uso indiscriminado dessas drogas no tratamento contra as doenças e ganho de crescimento e eficiência alimentar para animais em diferentes espécies e categorias (Teuber, 2001). Bactérias resistentes a diferentes antibacterianos são encontradas em leite de diversos animais de interesse agropecuário como bovinos, caprinos e ovinos e o gênero Staphylococcus predomina entre os mais comuns (Devriese et al., 1985; Harmon e Langlois, 1989; Pengov, 2001; Foschino et al., 2002; Devriese et al., 2002). Os estafilococos que não coagulam plasma são denominados Staphylococcus coagulase-negativos (SCN) e os que coagulam, Staphylococcus coagulase-positivos. Estas bactérias causam mastite em outros ruminantes (Devriese e Hommez, 1975; Adegoke, 1986; Kloos et al., 1997). Embora

*Mestranda do LSA.

**Graduanda Medicina Veterinária do LSA.

***Técnica de Nível Superior do LSA.

**** Professor Assoc II, Laboratório de Sanidade Animal/CCTA/Universidade Estadual do Norte Fluminense. Av Alberto Lamego, 2000, Horto, Campos dos Goytacazes, Rio de Janeiro CEP 28013-602. 
em número inferior aos existentes em vacas, os trabalhos com mastite por Staphylococcus spp. em búfalas são conhecidos (Varshney et al., 1993; Costa, 1999). Foi discutido no trabalho de Moroni et al. (2006) que as infecções intramamárias causadas por Staphylococcus spp. em búfalas podem não ter a mesma importância como nas demais espécies de ruminantes, quando a contagem de células somáticas no leite dos animais mostrou-se tímido, comparado aos números verificados em amostras de vacas infectadas por Staphylococcus spp. Dados importantes sobre a epidemiologia de $S$. aureus em ruminantes do estado do Rio de Janeiro apontaram para a existência de um clone majoritário circulante entre rebanhos. Os resultados demonstraram que $67 \%$ destes isolados foram sensíveis a todos os antibióticos testados (Aires-de-Sousa et al., 2007). No mesmo trabalho foi observado que $43 \%$ dos isolados de $S$. aureus, de três rebanhos diferentes de bubalinos, apresentaram tipos clonais diferentes, após a digestão dos produtos de PCR com enzima de restrição Smal e separação dos fragmentos pela técnica de eletroforese em gel de campo pulsante (PFGE). Outros isolados bacterianos, diferentes de Staphylococcus spp. e provenientes de amostras de leite foram descritos em rebanhos bubalinos destinados a produção de leite, no estado do Rio de Janeiro (Teixeira et al., 1996). Estudos com leite devem ser realizados por serem de importância não apenas scioeconômica e clínica, mas também do ponto de vista higiênico, decorrente do uso inadequado de drogas no tratamento de animais doentes e a possível seleção de microrganismos resistentes e sua introdução na cadeia alimentar, que pode levar a casos de alergias em indivíduos mais sensíveis à presença de resíduos dessas drogas (Teuber, 2001). Este trabalho descreve, pela primeira vez, a ocorrência de SCN com perfil de resistência a várias drogas testadas, presentes em rebanhos bubalinos de diferentes municípios do estado do Rio de Janeiro.

\section{Material e métodos}

Neste estudo, as búfalas examinadas pertenciam a criações mistas de rebanhos bovinos. Contudo, as ordenhas eram realizadas em separado das vacas em todas as propriedades estudadas. Foram coletadas 400 amostras de leite de búfalas sem sinais clínicos de doenças, testadas pelo CMT provenientes de seis municípios do estado do Rio de Janeiro, com maior concentração nas regiões dos Lagos e Norte/ Noroeste do estado. As amostras de leite foram coletadas e mantidas sob refrigeração até a chegada ao laboratório.

As amostras foram incubadas a $37^{\circ} \mathrm{C}$ por 12 horas e inoculadas em agar sangue (Merck, Alemanha), enriquecido com $5 \%$ de sangue de carneiro desfibrinado estéril, pela técnica de esgotamento com uso de alça de platina. Em seguida as placas foram incubadas a 37ํㅜ por até 24 horas e o padrão morfotintorial das colônias avaliado pela coloração de Gram. Os cocos Gram-positivos foram usados para os testes descritos para identificação como SCN. Foram seguidos os seguintes métodos para classificação bacteriana como pertencentes ao gênero Staphylococcus: teste de produção de catalase utilizando-se peróxido de hidrogênio (Sigma, EUA), lâminas para detecção de oxidase (Difco, EUA), coagulase em tubo (EDTA Plasma rabbit, Difco, EUA), assimilação de manitol em ágar Vogel-Johnson (Oxoide,
Inglaterra), padrão de hemólise em agar sangue (Merck, EUA) e atividade de deoxiribonuclease em ágar DNase (Merck, Alemanha). Nas placas de ágar sangue acompanhou-se a formação de zona de hemólise em torno das colônias crescidas. Os tubos para testes de produção de coagulase e lidos a cada duas horas. Para testes de detecção de atividade em ágar DNase utilizou-se um paquímetro para a leitura dos halos formados ao redor das colônias. A interpretação dos resultados em ágar Vogel-Johnson procederam a visualização de formação de halo amarelo em torno das colônias. Nestes testes as placas e tubos foram incubados em estufa bacteriológica a $37^{\circ} \mathrm{C}$ por 24 horas. Para confirmação das identificações, as de leituras das provas bioquímicas das galerias ID 32 Staph (bioMérieux, França) foram reveladas após 24 horas de incubação em câmara úmida a $37^{\circ} \mathrm{C}$, de acordo com as instruções do fabricante. Este método permite a realização de 32 testes bioquímicos miniaturizados, com interpretações realizadas pelo software em sistema automatizado (MiniApi®, bioMérieux, Itália). Os experimentos foram realizados em duplicatas e a cepa de $S$. aureus ATCC 25923 foi utilizada como controle positivo nos testes.

Para realização dos antibiogramas, o método utilizando discos para difusão em ágar de Kirby \& Bauer (Bauer et al., 1966). As colônias puras foram diluídas em salina estéril, com leitura de 0,5 na escala de McFarland empregando-se um fotômetro com leitura em Densidade Óptica a 550nm (Densimat, bioMérieux, França). Em seguida, com auxílio de suabe estéril, as células foram inoculadas de forma homogênea em ágar Muller Hinton (Merck, Alemanha). Após breve período para a secagem da superfície do ágar, foram colocados os discos (Multidisco®, Laborclin, PR, Brasil) de papel impregnados com as drogas e concentrações padronizadas: amoxicilina (AMO, $10 \mathrm{mg}$ ), clindamicina (CLI, 2mg), cefalotina (CFL, 30mg), penicilina G (PEN, 10U), oxacilina (OXA, $1 \mathrm{mg})$, tetraciclina (TET 30mg), ampicilina (AMP, 10mg), eritromicina (ERI, 15mg), sulfazotrim (SUT, $25 \mathrm{mg}$ ), gentamicina (GEN, 10mg), cefoxitina (CFO, 30mg) e vancomicina (VAN, 30mg). Estes testes foram realizados em duas repetições para confirmação dos resultados obtidos.

\section{Resultados}

Foram isoladas 197 cepas de Staphylococcus coagulasenegativas (SCN). As amostras SCN foram negativas para o teste de DNAse, exceto um isolado, classificado como S. sciuri com $99,9 \%$ de probabilidade pelo software do equipamento empregado.

Embora o isolado classificado como $S$. sciuri tenha apresentado perfil intermediário a vancomicina, verificou-se que a bactéria foi resistente frente aos beta-lactâmicos ampicilina e penicilina, intermediário a outro beta-lactâmico testado, a amoxicilina, e sensível a outros três, cefoxitima, cefalotina e oxacilina. Frente às demais drogas testadas, o isolado mostrou perfil intermediário (eritromicina e clindamicina) e de sensibilidade (sulfazotrim, gentamicina e tetraciclina). Para efeitos de comparação entre os demais isolados de SCN da mesma propriedade onde foi isolado $S$. sciuri, observou-se que outras $43(15,3 \%)$ amostras SCN foram isoladas. Entre elas 38 foram resistentes e apenas cinco foram sensíveis a penicilina, 18 foram sensíveis e 25 resistentes a ampicilina, 35 sensíveis e oito intermediários a 
eritromicina, cinco sensíveis, 25 intermediários e 13 resistentes a amoxicilina, 35 sensíveis e oito intermediários a clindamicina, 33 sensíveis, apenas um isolado intermediário e nove foram resistentes frente a tetraciclina. Todos os isolados de SCN da propriedade foram sensíveis frente a cefalotina, sulfazotrim e gentamicina, além de oxacilina e cefoxitima.

$\mathrm{Na}$ Tabela 1 estão os perfis de resistência dos isolados de SCN. Observa-se que os microrganismos apresentaram menor sensibilidade à penicilina $\mathrm{G}(28,46 \%)$ e à amoxicilina $(32,58 \%)$. Os antibióticos de maior impacto para as cepas isoladas foram sulfazotrim, gentamicina, vancomicina, cefalotina, cefoxitina e oxacilina, sendo que contra os últimos quatro os SCN tiveram $0 \%$ de resistência.

Tabela 1: Perfil de resistência frente a drogas antibacterianas, de 197 isolados de Staphylococcus coagulase-negativos provenientes de amostras de leite de búfalas, de seis municípios do estado do Rio de Janeiro.

\begin{tabular}{ccccccc}
\hline & \multicolumn{6}{c}{ Staphylococcus coagulase-negativo } \\
\hline Antibiograma & \multicolumn{2}{c}{ Sensível } & \multicolumn{2}{c}{ Intermediário } & \multicolumn{2}{c}{ Resistente } \\
\cline { 2 - 7 } & Total $(\mathrm{n})$ & $\%$ & Total(n) & $\%$ & Total(n) & $\%$ \\
\hline Penicilina G & 41 & 20,8 & - & - & 156 & 79,2 \\
Amoxicilina & 48 & 24,4 & 106 & 53,8 & 43 & 21,8 \\
Ampicilina & 90 & 45,7 & - & - & 107 & 54,3 \\
Eritromicina & 116 & 58,9 & 71 & 30,0 & 10 & 5,1 \\
Clindamicina & 164 & 83,3 & 31 & 15,7 & 02 & 1,0 \\
Tetraciclina & 181 & 91,9 & 03 & 1,5 & 13 & 6,6 \\
Sulfazotrim & 192 & 97,5 & 04 & 2,0 & 01 & 0,5 \\
Cefalotina & 195 & 99,0 & 02 & 1,0 & - & - \\
Gentamicina & 195 & 99,0 & 01 & 0,5 & 01 & 0,5 \\
Vancomicina & 196 & 99,5 & 01 & 0,5 & - & - \\
Cefoxitima & 197 & 100,00 & - & - & - & - \\
Oxacilina & 197 & 100,00 & - & - & - & - \\
\hline
\end{tabular}

$\mathrm{n}=$ número de amostras.

\section{Discussão}

Para a identificação de isolados de SCN pelo método API ID32 Staph, por um teste em galerias bioquímicas disponível comercialmente, até 24 espécies estafilocócicas são reconhecidas com $95,2 \%$ de capacidade de identificação correta dessas espécies (leven et al., 1995).

S. sciuri não faz parte da lista de bactérias mais comumente encontradas em infecções intramamárias de animais produtores de leite (Langlois et al. 1990). Contudo, este microrganismo pode ser isolado em amostras animais, além da espécie bovina (Deinhofer e Pernthaner, 1993). Uma análise mais aprofundada sobre a participação efetiva de $S$. sciuri na infecção intramamária ainda é necessária. Esta cepa de SCN foi classificada ao nível de espécie devido a sua característica frente ao glicopeptídeo vancomicina e sendo a única cepa com tal perfil entre todas as cepas SCN isoladas. Trabalhos que relatam o perfil de resistência de SCN de rebanhos bubalinos são escassos. Contudo, os dados existentes em bovinos, no Brasil, Costa et al. (2000) isolaram 33 cepas de SCN de glândulas mamárias de vacas com perfis de resistência diferentes dos apresentados no presente trabalho, utilizando os mesmos antibióticos testados (Tabela 1). Os SCN isolados pelos autores demonstraram $27,2 \%, 36,3 \%$,
$90,9 \%, 3 \%, 18,1 \%, 39,4 \%, 18,2 \%, 21,2 \%$ e $84,8 \%$ de resistência frente à tetraciclina, oxacilina, penicilina, cefalotina, gentamicina, vancomicina, eritromicina, sulfazotrim e ampicilina, respectivamente. Em leite de vacas com mastite, ficou comprovada a presença de cepas resistentes à penicilina em $S$. chromogenes e em três isolados de $S$. sciuri classificados como resistentes à cloxacilina, lincomicina e tetraciclina, ambos SCN (Devriese et al., 2002). Entre as cepas isoladas SCN no presente estudo, todas apresentaram um perfil de resistência inferior aos resultados obtidos por Costa et al. (2000), conforme observado na Tabela 1. Neste estudo, o baixo uso de antibióticos no tratamento contra mastite na espécie, de acordo com as informações obtidas nas propriedades envolvidas, poderia contribuir para este resultado, embora em outros estudos tenham relatado a presença de resíduos de antibióticos em leite de búfalas sadias (Sudershan e Bhat, 1995). A espécie SCN, S. sciuri, considerada uma das espécies estafilocócicas mais antigas e dispersas na natureza (Kloos et al., 1976) apresenta ampla variação de habitats, incluindo a pele de vários animais. Sua importância reside em um gene homólogo ao de resistência a meticilina, $m e c A$, presente em cepas de $S$. aureus (Couto et al., 1996) e por transmitir genes de resistência a $S$. aureus (WU et al., 1998). S. sciuri foi citado na provável transferência do gene mecA para outras bactérias, inclusive $S$. aureus (Kloos et al. 1997; Wu et al., 1998). A descrição de S. sciuri resistente a meticilina em leite bovino foi relatada, ainda que sua ocorrência nesta espécie animal tenha sido pouco citada na literatura disponível (GuerinFaublee et al., 2003) e não foi isolada no estudo de Langlois et al. (1990) com cepas provenientes de leite bovino. Recentemente, Stepanovic et al. (2001) demonstraram que $S$. sciuri pode apresentar vários fatores de virulência que ainda não haviam sido estudados com maiores detalhes. Os autores utilizaram 121 cepas da bactéria, a maioria originária de superfície de pele de cães. Na cepa isolada no presente trabalho, outras características importantes podem ser mencionadas e discutidas, tais como a produção de pigmento e produção de DNase. A produção de pigmento por cepas de $S$. aureus diminui os efeitos do sistema imune os quais seriam letais para a bactéria (Chamberlain et al., 1991). De acordo com o Manual Bergey Determinativo de Bacteriologia (Holt et al., 1994) algumas cepas de $S$. sciuri podem ser negativas para produção de pigmento. A produção de DNase, por $S$. sciuri, é considerada por alguns autores um fator importante para as cepas que apresentem esta característica (Stepanovic et al., 2001). Trata-se de uma exoenzima cujas prováveis funções seriam de degradação tecidual e invasão em uma infecção causada por outras espécies de SCN, tal como ocorre com S. epidermidis (Vuong et al., 2000). No presente trabalho, a produção de DNase pela cepa de $S$. sciuri foi comparada à cepa de $S$. aureus ATCC25923. Este resultado foi semelhante aos observados com 117 cepas de $S$. sciuri isolados de cães (Stepanovic et al., 2001).

A discussão da permanência de organismos resistentes a drogas no ambiente mamário é pertinente, tendo em vista estudos anteriores. O trabalho de Muhammad et al. (1993) demonstrou o fenômeno de transferência de plasmídeos que 
carreavam genes de resistência entre cepas de SCN e $S$. aureus provenientes de glândula mamária bovina, por meio de cultivo misto em caldo e em leite desnatado. Foi demonstrado que a transferência de resistência à estreptomicina foi bem-sucedida entre três cepas cultivadas em caldo e três cultivadas em leite. Sendo assim, os isolados com perfil de resistência a diferentes antibióticos detectadas neste trabalho poderiam contribuir para a possível transferência de genes entre bactérias que cohabitam a glândula mamária de búfalas. Esta linha de pensamento é compartilhada por outros autores, que sugerem esta possibilidade em rebanhos bovinos, cuja convivência entre cepas bacterianas, pertencentes a diferentes gêneros e espécies bacterianas isoladas do leite pode contribuir para tal fenômeno (Schlegelova et al., 2002). Além disso, nas propriedades cujas criações são mistas, bovinos com búfalos e ovinos, e que não estabelecem uma conduta adequada no momento da ordenha, podem oferecer oportunidade de transferência de cepas estafilocócicas entre animais e contribuir para a dispersão de cepas resistentes a antimicrobianos no ambiente rural. Em 16 municípios estudados na região Norte/Noroeste do estado do Rio de Janeiro, tal dispersão foi observada entre isolados de Staphylococcus aureus, genotipicamente iguais (Vieira-daMotta et al., 2001) e isolados de $S$. aureus (Vieira-da-Motta et al., 2000) e Staphylococcus coagulase-positivos com diferentes perfis de resistência a antibacterianos (principalmente aos beta-lactâmicos), entre propriedades e entre animais, em amostras provenientes de leite de vacas com mastite subclínica (Donatele et al., 2002). Os resultados encontrados no presente estudo com perfil de resistência entre os isolados de SCN da mesma propriedade de onde se isolou S. sciuri sugerem a ocorrência de circulação de material genético entre microrganismos, conforme observado por outros autores quando examinaram isolados de $S$. aureus entre outras propriedades leiteiras de criação de bovinos, no estado do Rio de Janeiro (Vieira-da-Motta et al., 2001). Utilizando a técnica de PCR com três metodologias para caracterização genotípica, Aires-de-Sousa et al. (2007), constataram cinco clones pela técnica de PFGE, de $S$. aureus presentes em leite de ruminantes, entre os quais rebanhos bubalinos, com um clone majoritário no estado do Rio de Janeiro e todos com perfis de resistência a diferentes drogas. Os autores sugeriram que os isolados de $S$. aureus encontrados são animaisespecíficos.

Este trabalho descreve a ocorrência de SCN em leite de búfalas com características de múltipla resistência a vários antibacterianos no estado do Rio de Janeiro. O perfil de resistência apresentado por estas bactérias pode favorecer a persistência de isolados resistentes em rebanhos bubalinos, caso o manejo nas propriedades não seja adequado e orientado. Também entendemos que devido às características observadas nos rebanhos estudados, criações mistas podem favorecer a ocorrência de isolados resistentes a antimicrobianos.

\section{Agradecimentos}

Aos produtores rurais, pela permissão da realização da pesquisa em suas propriedades. À FAPERJ, Processo E-26/171.541/ 2002, pelo apoio financeiro a OVM.

\section{Referências}

ADEGOKE, G. O. Characteristics of staphylococci isolated from man, poultry and some other animals. J Appl Bacteriol, v. 60, n.2, p. 97-102, 1986.

AIRES-DE-SOUSA, M.; PARENTE, C.E.S.R.; VIEIRA-DA-MOTTA, O. et al. Characterization of Staphylococcus aureus isolated from buffalo, bovine, ovine, and caprine milk samples from Rio de Janeiro State, Brazil. Appl Environ Microbiol, v. 73, n. 12, p. 3845-3849, 2007.

BAUER, A.,W.; KIRBY, M.M.; SHERRIS, J.C. et al. Antibiotic susceptibility testing by a standardized single disk method. Am J Clin Pathol, v. 45, p. 493-496, 1966.

CHAMBERLAIN, N.R.; MEHRTENS, B.G. ; XIONG, Z. et al. Correlation of carotenoid production, decreased membrane fluidity, and resistance to oleic acid killing in Staphylococcus aureus 18Z. Infect Immun, v. 59, n. 12, p.4332-4337, 1991.

COSTA, E. O. Controle e prevenção de mastite em bubalinos. In: TONHATI, H.; BARNABE, V.H.; BARUSELLI, P.S. (ed.). Bubalinos: sanidade, reprodução e produção. Funep, Jaboticabal-SP. 1999. p.6883.

COSTA, E.O.;BENITES, N.R.; GUERRA, J.L. etal. Antimicrobial susceptibility of Staphylococcus spp. isolated from mammary parenchymas of slaughtered dairy cows. J Vet Med B, v. 47, p.99-103, 2000.

COUTO, I.; DE LENCASTRE, H.; SEVERINA, E. et al. Ubiquitous presence of a mecA homologue in natural isolates of Staphylococcus sciuri. Microb Drug Resist, v.2(4), p.377-391, 1996.

DEINHOFER, M. e PERNTHANER, A. Staphylococcus spp. as mastitisrelated pathogens in goat milk. Vet Microbiol, v.43(2-3), p.161-166, 1995.
DEVRIESE, L. e HOMMEZ, J. Epidemiology of methicilin-resistant Staphylococcus aureus in dairy herds. Res Vet Sci, v.19, p.23-27, 1975.

DEVRIESE, L.A.; SCHLEIFER, K.H.; ADEGOKE, G.O. Identification of coagulase-negative staphylococci from farm animals. J Appl Bacteriol, v.58(1), p.45-55, 1985.

DEVRIESE, L.A.; BAELE, M.; VANEECHOUTTE, M. et al. Identification and antimicrobial susceptibility of Staphylococcus chromogenes isolates from intramammary infections of dairy cows. Vet Microbiol, v.87(2), p.175-82, 2002.

DONATELE, D.M.; MOTTA, O.V.; FOLLY, M.M. Antimicrobial profile of coagulase positive Staphylococcus spp strains from cows with subclinical mastitis in northern and northwestern regions of Rio de Janeiro, Brazil. Napgama, v.5(2), p.3 - 6, 2002.

FOSCHINO, R.; INVERNIZZI, A.; BARUCCO, R. et al. Microbial composition, including the incidence of pathogens, of goat milk from the bergamo region of italy during a lactation year. J Dairy Res, v.69(2), p.213-225, 2002.

GUERIN-FAUBLEE, V.; CARRET, G.; HOUFFSCHMITT, P. In vitro activity of 10 antimicrobial agents against bacteria isolated from cows with clinical mastitis. Vet Rec, v.152(15), p.466-471, 2003.

HARMON, R.J.; LANGLOIS, B.E. Mastitis due to coagulase-negative Staphylococcius species. Agri-Practice, v.10, p.29-34, 1989.

HOLT, J. G.; KRIEG, N.R.; SNEATH, P.H.A. et al. Bergey's Manual of Dterminative Bacteriology. Baltmore, Maryland. Williams and Wilkins, p.542 -549, 1994.

IEVEN, M.; VERHOEVEN, J.; PATTYN, S. R. et al. Rapid and economical method for species identification of clinically significant coagulasenegative staphylococci. J Clin Microbiol, v.33(5), p.1060-1063, 1995. 
KLOOS, W.E.; SCHLEIFER, K.H.; SMITH, R.F. Characterization of Staphylococcus sciurisp. nov. and its subspecies. Int J Syst Bacteriol, v.26, p.22-37, 1976.

KLOOS, W. E.; BALLARD, D. N.; WEBSTER, J. A. et al. Ribotype delineation and description of Staphylococcus sciuri subspecies and their potential as reservoirs of methicillin resistance and staphylolytic enzyme genes. Int J Syst Bacteriol, v.47(2), p.313-23, 1997.

LANGLOIS, B.E.; PARLINDUNGAN, A.K.; HARMON, R.J.; et al. Biochemical characteristics of Staphylococcus aureus species of human and bovine origin. J Food Prot, v.53(2), p.119-126, 1990.

MORONI, P.; SGOIFOROSSI, C.; PISONI, G. et al. Relationships between somatic cell count and intramammary infection in buffaloes. J Dairy Sci. v. 89, p. 998-1003, 2006.

MUHAMMAD, G.; HOBLET, K.H.; JACKWOOD, D.J.; et al. Interspecific conjugal transfer of antibiotic resistance among staphylococci isolated from the bovine mammary gland. Am J Vet Res, v. 54(9), p.1432-1440, 1993.

PENGOV, A. The role of coagulase-negative Staphylococcus spp. and associated somatic cell counts in the ovine mammary gland. J Dairy Sci, v.84(3), p.572-574, 2001.

SCHLEGELOVA, J.; BABAK, V.; KLIMOVA, E. et al. Prevalence of and resistance to anti-microbial drugs in selected microbial species isolated from bulk milk samples. J Vet Med B Infect Dis Vet Public Health, v.49(5), p.216-225, 2002.

STEPANOVIC, S.; VUKOVIC, D.; TRAJKOVIC, V. et al. Possible virulence factors of Staphylococcus sciuri. FEMS Microbiol Lett, v.199, p.47-53, 2001.
SUDERSHAN, R. V.; BHAT, R. V. A survey on veterinary drug use and residues in milk in Hyderabad. Food Addit Contam, v.12(5), p.645-650, 1995.

TEIXEIRA, L. M.; MERQUIOR, V. L.; VIANNI, M. C. et al. Phenotypic and genotypic characterization of atypical Lactococcus garvieae strains isolated from water buffalos with subclinical mastitis and confirmation of $L$. garvieae as a senior subjective synonym of Enterococcus seriolicida. Int J Syst Bacteriol, v.46(3), p.664-668, 1996.

TEUBER, M. Veterinary use and antibiotic resistance. Curr Opin Microbiol, v.4(5), p.493-499, 2001.

VARSHNEY, J.P.; KAPUR, M.P.; SHARMA, A. Study on some biochemical characteristics of Staphylococcus aureus of buffalo mammary origin. Comp Immun Microbiol Infect Dis, v.16(4), p.317-321, 1993.

VIEIRA-DA-MOTTA, O., DONATELE, D.M., OLIVEIRA, P.R. et al. Staphylococcus aureus sensíveis à meticilina provenientes de leite mastítico no Estado do Rio de Janeiro. Braz J Vet Sci, v.7(2), p.123$126,2000$.

VIEIRA-DA-MOTTA, O., SAKYIAMA, C.C.H., FOLLY, M.M. Detection of different strains Staphylococcus aureus strains in bovine milk from subclinical mastitis using PCR and traditional techniques. Braz J Microbiol, v.32, p.27-31, 2001.

VUONG, C.; GÖTZ, F.; OTTO, M. Construction and characterization of an agrdeletion mutant of Staphylococcus epidermidis. Infect Immun, v.68, p.1048-1053, 2000.

WU, S.; DE LENCASTRE, H.; TOMASZ, A. Genetic organization of the mecA region in methicillin-susceptible and methicillin-resistant strains of Staphylococcus sciuri. J Bacteriol, v.180(2), p.236-42, 1998. 